Research Paper:

\title{
Comparative Effect of Behavioral Activation Treatment for Depression and Acceptance and Commitment Therapy Matrix on the Depression of College Students
}

\author{
Amin Khaledinia (D), Behnam Makvandi ${ }^{1^{*}}$ (D) Parviz Asgari ${ }^{1}$ (D) Reza Pasha $^{1}$ (i) \\ 1. Department of Psychology, Faculty of Humanities, Ahvaz Branch, Islamic Azad University, Ahvaz, Iran.
}

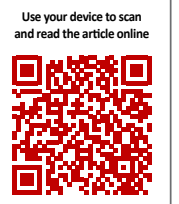

Citation Khaledinia A, Makvandi B, Asgari P, Pasha R. Comparative Effect of Behavioral Activation Treatment for Depression and Acceptance and Commitment Therapy Matrix on the Depression of College Students. Avicenna J of Neuropsychophysiology. 2018; 5(2):63-72. http://dx.doi.org/10.32598/ajnpp.5.2.63

oil) http://dx.doi.org/10.32598/ajnpp.5.2.63

\section{c) (1) (\$)}

Article info:

Received: 03 Oct 2017

Accepted: 10 Feb 2018

Available Online: 01 May 2018

Keywords:

Matrix, Acceptance and Commitment Therapy (ACT), Behavioral Activation Treatment for Depression (BATD)

\section{ABSTRACT}

Background: Depression is a severe and debilitating mental disorder that afflicts many people worldwide.

Objectives: This study tried to compare the effectiveness of Behavioral Activation Treatment for Depression (BATD) and Acceptance and Commitment Therapy (ACT) matrix on the depression of college students.

Materials and Methods: The present study is an experimental design using a pre-test and Post-test with a control group. The therapeutic intervention in the experimental group was implemented in eight 1-h sessions once per week for female students between 18 and 35 years old, who had depression symptoms. The participants in the experimental and control groups responded to the Beck Depression Inventory second edition (BDI-II) before and after the intervention, and in followup (4 weeks after the end of the intervention).

Results: According to the analysis of covariance, the ACT matrix and BATD reduced the symptoms of depression. There was no significant difference between the two groups in depression (ACT matrix and BATD) ( $P=0.999)$. This indicates the almost identical effect of the ACT matrix and BATD. Eta coefficient shows that matrix and BATD explain 0.64 of depression and these results were sustained in the follow-up stage.

Conclusion: Both ACT matrix and BATD can significantly reduc the symptoms of depression in college students.

\section{* Corresponding Author:}

Behnam Makvandi, PhD.

Address: Department of Psychology, Faculty of Humanities, Ahvaz Branch, Islamic Azad University, Ahvaz, Iran.

Tel: +98 (937) 8709698

E-mail: makvandi_b@yahoo.com 


\section{Introduction}

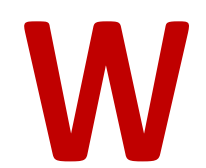

ith a prevalence of $17 \%$, depression is the most common psychiatric disorder in the world. No wonder it is called "common cold" in the world of mental conditions $[1,2]$. In recent years, the students' depression and anxiety have reached alarming rates. According to Nejat et al., student life has created depression and anxiety and affected students' mental health in recent years. The students' stresses, as well as their biological and psychological readiness, lead to the increased rates of mental disorders in them [3]. Many students can easily adapt to the new environment, while others hardly adapt to new conditions adapt to new scientific or psychological conditions [4]. Because of such challenges, a high proportion of students are at risk of developing psychological illnesses, including depression [5].

There are many psychological interventions for depression and its dependent variables, but few have been able to prove their effectiveness in clinical trials [6]. Of the third-generation therapies, Behavioral Activation Treatment for Depression (BATD) and Acceptance and Commitment Therapy (ACT) may be particularly useful in the treatment of emotional difficulties in depressive disorders because of the emphasis they place on eliminating avoidance and encouraging activation $[7,8]$. The goals of these therapies comply with the previouslydescribed situation characterized by the avoidance of unpleasant private events related to the disease and a reduction in involvement in relevant activities. Both therapies have shown good results in the psychological treatment of cancer survivors $[7,8]$.

Behavioral activation interventions have been mainly used to treat depressive disorders, symptoms, with efficacy such that behavioral activation is now considered an empirically-validated treatment for depression [6, 9, 10]. In one of the more compelling studies, behavioral activation was comparable to antidepressant medication and superior to cognitive therapy in treating severe depression, and its results [11] lasted after 2 years follow-up [12].

The ACT is hugely effective in helping clients who are "sticking" to unhealthy thinking patterns by giving support or confidence to align their values with their thoughts and actions [13-15]. However, the ACT model is complex, and it is not always easy to use. ACT Matrix is an seamless fusion of the 6 cores of the ACT hexaflex processes (i.e. cognitive defusion, acceptance, contact with the present moment, observation of the self, values, and committed actions) into a simplified, easy-touse approach [16]. The matrix is an application that emphasizes the importance of the context of inquiry in a

\section{The Psychological Flexibility Model Matrix Kevin L. Polk, Ph.D.}

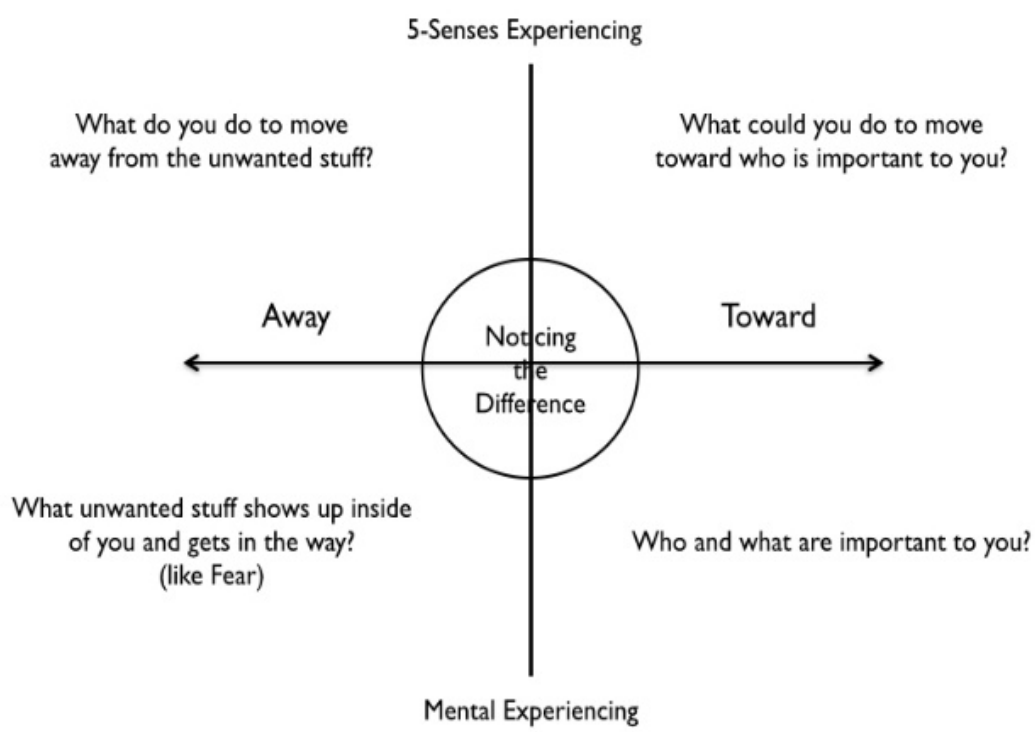

Figure 1. ACT model 
particular approach designed to identify what works in a specific context (Figure 1).

A functional contextual perspective condition, in which people interact with their life situations, determines the consequences of their behaviors and usefulness in reaching their important issues. Trying to change one's feelings or thoughts might or, more often, might not work to move a person toward what is important [17]. ACT matrix is an approach based on route selection and upgrading the ability of individuals to approach worthwhile goals, despite the problems in life. Therefore, in the matrix model, the viewpoints of clients are considered as the basis of treatment. Then, they will be helped to achieve a live, purposeful, and meaningful life by examining the actions which get them close to values and compassion in commitment and changing their strategies [18].

Until now, studies on the Act matrix are scarce. Mirsharifa et al. have shown that using the ACT matrix is a useful way to improve depression and enhance psychological capital among patients [19]. Another study results showed that the ACT matrix has significantly reduced the symptoms of self-injury and improved quality of life in adolescents with borderline personality disorder symptoms [18].

According to what was mentioned above, the present study aims to analyze the effectiveness of ACT matrix and BATD in the treatment of depressive symptoms in college students. The importance of occurring such a study lies, firstly, in the fact that only ACT (matrix) has been studied in depression symptoms on a group basis and, secondly, as far as we know, it has never been compared to BATD. The first perspective is essential concerning improving the efficiency of psychological treatments. The second is especially relevant with regard to the purpose of identifying responsible factors for the clinical change.

\section{Materials and Methods}

This study was a trial with a control group that used the quasi-experimental design. The statistical population consisted of all depressed students of Payame Noor University of Imam Khomeini, who volunteered to participate in the study from October to November 2018.

For this purpose, first, notices at university and cyberspace were disturbed. Then, the depressed students were determined by using the Beck depression inventory. The subjects with depressive disorder were selected by random cluster sampling method. Next, 45 of them were randomly selected and divided into 3 groups (15 people in each group). Of the 3 groups, two groups received BATD [20] and ACT matrix [16] interventions and a 1-month follow-up.

The inclusion criteria included: 1 . Age ranged 18-35 years; 2 . The depression diagnoed according to the Beck depression inventory the second edition (BDI-II) and cut-off point (score 17 and above in depression inventory II); 3. Not to be under any psychological or medicinal treatment 6 months before entering the research; and 4. Only female students included. The exclusion criteria included: 1 . Unwilling to participate in the research; 2. Having the history of psychotic disorders, bipolar disorder, and severe personality disorders; 3 . Having a physical condition, where depression is attributable to its complications; 4. Lacking psychoactive substance use and addiction to drugs or alcohol; and 5. Being absent in 2 treatment sessions (Table 1 ).

\section{Study instrument}

The Beck depression questionnaire, the second edition (BDI-II), contains 21 questions that are designed to measure the feedback and symptoms of depressed patients. The test consists of 21 items related to different symptoms that subjects must answer on a 4-point scale from 0 to 3 . The total scores in this questionnaire are classified as 0-13 indicating no or minimum depression, 14-20 mild depression, 20-28 moderate to depression, and 28-63 severe depression. In this study, the cut-off point was considered BDI-II $\geq 17$. In the study of Dobson and Mohammad Khani, the total reliability score was 0.91 . The internal consistency of the test for Iranian students was 0.87 and its test-retest validity was 0.73 . In this study, the reliability coefficients of the depression questionnaire were calculated, using the Cronbach alpha value as 0.91 for the whole scale, indicating the desired reliability coefficients of the questionnaire.

The collected data were analyzed in SPSS V. 23. Descriptive statistics, including Mean and Standard Deviation (SD), as well as the analytical, statistical tests, including analysis of covariance (ANCOVA) and Levene's test for homogeneity of variances, were used. $P$ values of less than 0.05 were considered significant. After calculating the scores of pre-test and Post-test in 3 groups, the Levene's test for homogeneity of variances and ANCOVA were performed to evaluate the effectiveness of the ACT matrix and BATD on the depression of students (Table 2). 
Table 1. The content of treatment sessions for the ACT matrix

\begin{tabular}{|c|c|}
\hline Sessions & Practicing the 6-Step Approach to Use Act Matrix and Integrate a Relationship-Focused Approach to Act \\
\hline First & Present the ACT matrix point of view to clients and prompt clients to evaluate the usefulness of moving away behavior. \\
\hline Second & $\begin{array}{l}\text { Help clients notice and name their stuck loops and find the difference between what can be controlled ( } 5 \text { senses } \\
\text { experience) and what gets more sticky as one attempts to control it (inner experience). }\end{array}$ \\
\hline Third & Learn how to use the Hooks Worksheet and metaphor to promote defusion. \\
\hline Fourth & $\begin{array}{c}\text { Practice validation skills through the art of yessing and learn how to engage clients in the skills of verbal aikido, using } \\
\text { the Verbal Aikido Worksheet. }\end{array}$ \\
\hline Fifth & $\begin{array}{c}\text { Learn how to promote self-compassion and practice prompting behavior change through the perspective-taking } \\
\text { interview exercise. }\end{array}$ \\
\hline Sixth & $\begin{array}{l}\text { Practice using the bridging questions to get precise and actionable feedback from clients. Learn how to hold a consis- } \\
\text { tent functional contextual stance in your clinical work. }\end{array}$ \\
\hline \multicolumn{2}{|c|}{ Table 2. The content of treatment sessions for BATD } \\
\hline Sessions & Meeting Titles \\
\hline First & An explanation of depression and the behavioral activation model, as well as the introduction of a daily review form \\
\hline Second & Reviewing the task of the previous session and training "self-examination" \\
\hline Third & Homework, the relationship of behavior, thoughts, and emotions, and functional analysis of patient activities \\
\hline Fourth & Task review, functional analysis, reinforcement of effective coping practices, values \\
\hline Fifth & Homework review, functional analysis, strengthening effective coping practices \\
\hline Sixth & Reviewing homework, reviewing and summarizing, and teaching how to deal with depression in the future \\
\hline
\end{tabular}

AJNPP

\section{Results}

In the ACT matrix group, the most frequent age groups (40\%) belonged to $18-20$ and $21-25$ years. In the BATD group, the subjects in the age groups of 31 to 35 and 21 to 25 years old were the most (33.3\%) and the least (6.7\%) frequent subjects, respectively. In the ACT matrix group, single subjects were about $86.7 \%$, and married subjects accounted for $13.3 \%$ of the samples. In the BATD group, single subjects were approximately $73.3 \%$ and married subjects accounted for $26.7 \%$ of the samples. In the control group, single subjects were $86.7 \%$ and married subjects accounted for $13.3 \%$ of the samples.

According to Table 3, the Mean \pm SD values of ACT matrix, BATD, and the control groups were 22.60 \pm 5.84 , $26.93 \pm 7.22$, and $28.53 \pm 7.21$, respectively, in the pre-test stage. In the Post-test stage, the Mean $\pm S D$ values of ACT matrix, BATD, and the control group were $11.67 \pm 6.41$, $11.87 \pm 10.08$, and $28.60 \pm 10.94$, respectively. In the follow-up stage, the Mean $\pm S D$ values of ACT matrix, BATD, and the control groups were $8.73 \pm 6.36,7.73 \pm 7.89$, and $26.60 \pm 8.69$, respectively.

As presented in Table 4, the homogeneity of variances in 3 groups is significant for all variables in the research. In other words, considering the lack of the significance of $F$ (Levene's test), the zero assumption for the homogeneity of the variances of the 3 groups in the variables of the research is confirmed. However, when the sample size is equal, the significance of the Levenes' test does not have a significant effect on the alpha level.

As presented in Table 5, the zero assumption for the normal distribution of the scores of 3 groups in the depression variables is confirmed. Thus, the assumption of the normal distribution of the scores in the pre-test of all 3 groups is confirmed. According to Table 6, the $F$ value of the interaction for all the variables in the research is not significant. Therefore, the homogeneous assumption of regression is confirmed. 
Table 3. Mean $\pm S D$ of depression scores in the experimental and control groups in the pre-test, post-test, and follow-up stages

\begin{tabular}{|c|c|c|c|c|}
\hline Variable & Stage & Index Group & Mean $\pm S D$ & n \\
\hline & & Matrix (ACT) & $22.60 \pm 5.84$ & 15 \\
\hline & Pre-test & BATD & $26.93 \pm 7.22$ & 15 \\
\hline & & Control & $28.53 \pm 7.21$ & 15 \\
\hline & & Matrix (ACT) & $11.67 \pm 6.41$ & 15 \\
\hline \multirow[t]{5}{*}{ Depression } & Post-test & BATD & $11.87 \pm 10.08$ & 15 \\
\hline & & Control & $28.60 \pm 10.94$ & 15 \\
\hline & & Matrix (ACT) & $8.73 \pm 6.36$ & 15 \\
\hline & Follow-up & BATD & $7.73 \pm 7.89$ & 15 \\
\hline & & Control & $26.60 \pm 8.69$ & 15 \\
\hline
\end{tabular}

ACT: Acceptance, and Commitment Therapy; BATD: Behavioral Activation Treatment for Depression

Table 4. Levene's test on the default of the equation of variance in 3 groups

\begin{tabular}{ccccc}
\hline Variable & F & F1 & F2 & Sig. \\
\hline Depression & 1.40 & 2 & 42 & 0.257
\end{tabular}

AJNPP

As presented in Table 7, using pre-test control, there is a significant difference between the depressed students of the experimental and control groups in terms of the dependent variable of depression $(\mathrm{P}<0.0001 ; \mathrm{F}=5.68$; Eta $=0.39$ ). In other words, $39 \%$ of the individual differences in Post-test depression scores relate to the effect of the ACT matrix and BATD. The statistical power is 0.999. In other words, if this research is repeated 1000 times, only 1 factor may be confirmed by the wrong hypothesis.
As presented in Table 8, there is a significant difference between the depressed students in the pre-test control $(P<0.0001 ; F=17.65)$. The effect or difference is 0.48 . In other words, $48 \%$ of individual differences in the Posttest scores of depression are related to the impact of the ACT matrix and BATD. Statistical power is 1.00 which means there was no possibility of a second type error.

As presented in Table 9, there is a significant difference between the mean Post-test depression of depressed students in the ACT and BATD groups $(P=0.0001)$. In

Table 5. The Kolmogorov-Smirnov test checking the presumption of the normal distribution of depression scores

\begin{tabular}{|c|c|c|c|c|c|c|c|c|c|c|c|c|}
\hline \multirow{2}{*}{ Normalization } & \multirow{2}{*}{ Groups } & \multicolumn{3}{|c|}{ Kolmogorov-Smirnov } & \multirow{2}{*}{ Groups } & \multicolumn{3}{|c|}{ Kolmogorov-Smirnov } & \multirow{2}{*}{ Groups } & \multicolumn{3}{|c|}{ Kolmogorov-Smirnov } \\
\hline & & $\mathbf{P}$ & df & Statistic & & $\mathbf{P}$ & df & statistic & & $\mathbf{P}$ & df & Statistic \\
\hline Depression & $\begin{array}{l}\text { Matrix } \\
\text { (ACT) }\end{array}$ & 0.208 & 15 & 0.187 & BAT & 0.081 & 15 & 0.208 & control & 0.002 & 15 & 0.155 \\
\hline
\end{tabular}

AJNPP

Table 6. Homogeneity of regression slopes of the variables of the 3 groups

\begin{tabular}{cccccccc}
\hline \multirow{2}{*}{ Variable } & Source Changes & \multicolumn{2}{c}{ Pre-test, Post-test } & & \multicolumn{2}{c}{ Pre-test-Follow-up } \\
\cline { 3 - 4 } Depression & $\begin{array}{c}\text { G (Interactions) } \\
\text { Inoup } \times \text { pre-test }\end{array}$ & $\mathbf{P}$ & & $\mathbf{F}$ Source Changes & $\mathbf{F}$ (Interactions) & $\mathbf{P}$ \\
\hline
\end{tabular}


Table 7. Multivariate analysis of covariance on the post-test depression in the experimental and control groups with pre-test control

\begin{tabular}{cccccccc}
\hline Presumptions & Size & $\mathbf{F}$ & df Hypothesis & df Error & Eta & P & Statistical Power \\
\hline Pillai's trace & 0.66 & 4.46 & 8 & 72 & 0.33 & 0.001 & 0.993 \\
\hline Wilk's lambda & 0.36 & 5.68 & 8 & 70 & 0.39 & 0.001 & 0.999 \\
Hotelling's trace & 1.63 & 6.96 & 8 & 68 & 0.45 & 0.001 & 0.01 \\
\hline Roy's Largest root & 1.58 & 14.28 & 4 & 36 & 0.61 & 0.001 & 0.01 \\
\hline
\end{tabular}

AJNPP

Table 8. ANCOVA of post-test depression on the experimental and control groups with pre-test control

\begin{tabular}{|c|c|c|c|c|c|c|c|c|}
\hline Variable & $\begin{array}{c}\text { Source of } \\
\text { Change }\end{array}$ & $\begin{array}{l}\text { Sum of } \\
\text { Squares }\end{array}$ & df & $\begin{array}{l}\text { Average } \\
\text { Squares }\end{array}$ & $\mathbf{F}$ & $\mathbf{P}$ & Eta & $\begin{array}{c}\text { Statistical } \\
\text { Power }\end{array}$ \\
\hline \multirow{3}{*}{ Depression } & Pre-test & 17.46 & 1 & 17.46 & 0.231 & 0.634 & 0.01 & 0.076 \\
\hline & Group & 2669.82 & 2 & 1334.91 & 17.65 & 0.0001 & 0.64 & 0.01 \\
\hline & Error & 2872.67 & 38 & 75.59 & & & & \\
\hline
\end{tabular}

AJNPP

Table 9. Bonferroni post hoc test between mean scores of post-test depression in the experimental and control groups with pre-test control

\begin{tabular}{cccc}
\hline Groups & Mean & & P \\
\cline { 3 - 4 } & & BATD & Control \\
Matrix (ACT) & 11.67 & 0.999 & 0.0001 \\
BATD & 11.87 & - & 0.0001 \\
Control & 28.60 & - & - \\
\hline
\end{tabular}

AJNPP

ACT: Acceptance and Commitment Therapy; BATD: Behavioral Activation Treatment for Depression

Table 10. Multivariate analysis of covariance on the experimental and control groups with pre-test control

\begin{tabular}{cccccccc}
\hline Presumptions & Size & $\mathbf{F}$ & df Hypothesis & df Error & Eta & P & Statistical Power \\
\hline Pillai's trace & 0.77 & 5.63 & 8 & 72 & 0.38 & 0.001 & 0.999 \\
\hline Wilk's lambda & 0.29 & 7.41 & 8 & 70 & 0.46 & 0.001 & 0.01 \\
\hline Hotelling's trace & 2.19 & 9.34 & 8 & 68 & 0.52 & 0.001 & 0.01 \\
\hline Roy's Largest root & 2.09 & 18.85 & 4 & 36 & 0.67 & 0.001 & 0.01 \\
\hline
\end{tabular}

AJNPP

other words, the ACT matrix reduced the depression of the experimental group.

Besides, there is a significant difference between the mean Post-test depression of depressed students of the BATD group and the control group $(P=0.0001)$. In other words, BATD decreased the depression of the experimental group compared with the mean of the control group.

There was no significant difference in depression between the two experimental groups and BATD $(P=0.999)$. This indicates the almost identical effect of the ACT matrix and BATD to reduce depression. 
Table 11. One-way ANCOVA on the experimental and control groups with pre-test control

\begin{tabular}{|c|c|c|c|c|c|c|c|c|}
\hline Variable & $\begin{array}{c}\text { Statistical } \\
\text { Power }\end{array}$ & Eta & $\mathbf{P}$ & $\mathbf{F}$ & $\begin{array}{l}\text { Average } \\
\text { Squares }\end{array}$ & df & $\begin{array}{l}\text { Sum of } \\
\text { Squares }\end{array}$ & $\begin{array}{c}\text { Source of } \\
\text { Change }\end{array}$ \\
\hline \multirow{3}{*}{ Depression } & 0.129 & 0.02 & 0.409 & 0.697 & 30.56 & 1 & 30.56 & Pre-test \\
\hline & 0.01 & 0.64 & 0.0001 & 35.04 & 1534.54 & 2 & 3071.08 & Group \\
\hline & & & & & 43.82 & 38 & 1665. 19 & Error \\
\hline
\end{tabular}

Table 12. Bonferroni test follow-up in the experimental and control groups with pre-test control

\begin{tabular}{ccccc}
\hline & Groups & Mean & & P \\
\cline { 3 - 4 } & & & BATD & Control \\
\hline 1 & Matrix (ACT) & 8.73 & 0.411 & 0.0001 \\
\hline 2 & BATD & 7.73 & - & 0.0001 \\
3 & Control & 26.60 & - & AJNPP
\end{tabular}

ACT: Acceptance, and Commitment Therapy; BATD: Behavioral Activation Treatment for Depression

According to Table 10, in the follow-up stage with the pre-test control, there is a significant difference between the depressed students of the experimental and control groups in terms of the dependent variable of depression ( $P<0.001 ; F=7.41 ; E t a=0.46)$. In other words, $46 \%$ of the individual differences in depression scores relate to the continuation of the effect of the ACT matrix and BATD. Statistical power is 0.01 , which means zero possibility of a second type error.

As presented in Table 11, there is a significant difference among depressed students in the experimental and control groups regarding depression in the followup stage and pre-test $(P<0.0001 ; F=35.04 ; E t a=0.44)$. In other words, $64 \%$ of individual differences in depression scores are related to the continuation of the effect of the ACT matrix and BATD. The statistical power is 0.01 , indicating no possibility of a second type error. As presented in Table 12, in the follow-up stage, there is a significant difference between the depressed students in the ACT matrix with the control group $(\mathrm{P}=0.0001)$. In other words, the ACT matrix continuously lowered the depression of students in the experimental group. Also, there was a significant difference between the means of depressed students in the BATD group with the control group ( $\mathrm{P}=0.0001)$. In other words, the BATD group continuously reduced the depression in the experimental group.

There was no significant difference between the two groups (ACT and BATD) in terms of depression
$(P=0.411)$. This suggests the almost identical effect of ACT and BATD in the durability of depression reduction.

\section{Discussion}

The results showed a significant difference between the experimental and control groups in the mean scores of depression in the pre-test, Post-test, and follow-up stages. According to the findings, the ACT matrix and BADT decreased depression among college students. The research background shows that the obtained results in this study are consistent with the results of some other studies [6, 9-11, 13-15, 21].

Fernandez and Barakamarial compared the effect of BATD and cognitive therapy on reducing negative thoughts in anxious conditions in students. The analysis of the measurements before and after the treatment showed that both conditions were effective in reducing the severity of anxiety response. However, according to what they observed, the effect of behavioral activation showed a significant decrease [22]. In a study by Saman et al. on the efficacy of BATD, participants agreed that BATD is necessary to develop positive behaviors and strategies for the treatment of depression. Patients agreed that the program was sustainable and emphasized the potential of improving symptoms of depression [6].

BATD is designed to gradually increase positive activities in achieving long-term goals based on values [23]. To explain its effectiveness, therapeutic measures, in addition 
to the behavioral activation models, should be consciously used based on the sustainability of their benefits. Both clinicians and patients appreciated a variety of activities in the program structure, especially those that provide increased stimulation and exposure. This finding was in line with other research results on the effectiveness of behavioral activation [23]. Depression is one of the psychological factors characterized by a loss of sense of control over emotion and behavior, and the depressed person is suffering a lot from this problem [24].

These changes usually cause the patient's experience of negative feelings, the disruption of interpersonal, social, and occupational functions followed by continuous nervous system physiological stimulation [25]. To explain the effectiveness of the ACT matrix in reducing depression, several possibilities can be considered. For example, the ACT can target the avoidance pattern. During the interventions, the reduction of the experimental avoidances is regarded as a mediator of change in the symptoms of depression [26].

Avoidance is defined as an effort to escape the depressing thoughts and memories that are brought to the consciousness of the depressed person [27]. In this treatment, accepted practices and discussions about the person's values and goals lower depression in depressed college students. This treatment teaches people how to let go of their beliefs of avoidance and accept them instead of trying to control them [28].

The effectiveness of group therapy on depression, cognitive-behavioral avoidance, and quality of life of students have proven its efficacy [6]. Although ACT was established as an inferiority-based approach, the first randomized controlled clinical trial evaluated the effectiveness of this treatment on depression. The clinical results obtained by Zettle and Hayes indicated that the treatment of admission and commitment was effective in treating depression and resulted in a more rapid decrease in depressed thoughts [29].

Gonzales Fernandez and associates considered BATD and ACT an appropriate and useful treatment of emotional problems in patients with cancer. The effectiveness of these two treatments was evaluated and compared with each other. The findings indicated that both treatments were superior to all studied variables. However, there was a significant difference between the two methods in the ACT in the treatment of social defect and avoidance/rumination. The BATD and ACT, which are applied collectively, are useful in the treatment of common emo- tional problems, such as anxiety and depression in cancer survivors [30].

Thus, in this study, the ACT matrix seems to help depressed college students to reflect on their experiences and gain mental stability. Hope is another psychological capital component. Hope is a cognitive process, but it has emotional consequences. Thus, hope is not a passive emotion that only appears in the dark moments of life; but it is a cognitive process that people actively seek to reach their goals. Therefore, hope is a process through which the person determines his or her purposes, devises approaches toward them, and creates and maintains the motivation necessary to carry out these approaches [31].

There are several limitations to the present study, and the results should be interpreted with caution. First of all, our sample size is relatively small. Secondly, we did not use the male gender. These data must be replicated in larger samples of both genders. Also, we have only used the BDI-II; so, other questionnaires, such as Hamilton Inventory can be used in further studies. In summary, based on our results, depressed patients may have different activities compared to the healthy population.

In conclusion, It can be concluded that depression is affected by many factors and has confounding variables similar to those of anxiety and stress [32]. Such variables can be exacerbated by socioeconomic status, living situation, education level, and family life [33]. Because of these combined risk factors, college students often need more treatment and intervention [34]. Although there are research studies on the depression and treatment outcomes among college students, they are a few and their methodologies are inconsistent. Future studies should focus on the developing reasonable benchmark of depression and treatment outcomes in the college population and integrating such outcome data into college mental health practice [35].

\section{Ethical Considerations}

\section{Compliance with ethical guidelines}

All ethical principles were considered in this article. The participants were informed about the purpose of the research and its implementation stages; they were also assured about the confidentiality of their information; Moreover, They were allowed to leave the study whenever they wish, and if desired, the results of the research would be available to them. 
Funding

This article was extracted from a PhD. thesis of Amin Khaledinia in Department of Psychology, Faculty of Humanities, Ahvaz Branch, Islamic Azad University, Ahvaz.

\section{Authors' contributions}

Study design: Amin Khaledinia and Behnam Makvandi; Data collection and analysis: Amin Khaledinia; Manuscript preparation: Amin Khaledinia, Behnam Makvandi, Parviz Asgari, Reza Pasha.

\section{Conflict of interest}

The authors declared no conflict of interest.

\section{References}

[1] Adock BJ, Sadock VA, Ruiz P. Kaplan \& Sadock's synopsis of psychiatry: Behavioral sciences/clinical psychiatry. Philadelphia: Lippincott Williams \& Wilkins; 2014

[2] American Psychiatric Association. Diagnostic and statistical manual of mental disorders. $5^{\text {th }}$ ed. Washington, DC: American Psychiatric Association; 2013. [DOI:10.1176/appi.books.9780890425596]

[3] Nejat S, Montazeri A, Halakouei Nayeni K, Mohammad K, Majdezadeh SR. The World Health Organization quality of Life (WHOQOLBREF) questionnaire: Translation and validation study of the Iranian version. Journal of School of Public Health and Institute of Public Health Research. 2006; (4)4:1-12.

[4] Manos RC, Kanter JW, Busch AM. A critical review of assessment strategies to measure the behavioral activation model of depression. Clinical Psychology Review. 2010; 30(5):547-61. [DOI:10.1016/j. cpr.2010.03.008] [PMID]

[5] Khubchandani J, Brey R, Kotecki J, Kleinfelder J, Anderson J. The psychometric properties of PHQ-4 depression and anxiety screening scale among college students. Archives of Psychiatric Nursing. 2016; 30(4):457-62. [DOI:10.1016/j.apnu.2016.01.014] [PMID]

[6] Sudani M, Sharalinia K, Valian A, Khojasteh Mehr R. The effectiveness of behavioral activation therapy on depression symptoms and cognitive-behavioral avoidance for students. Quarterly Journal of Social Work. 2016; 5(4):25-31

[7] Collado A, Long KE, MacPherson L, Lejuez CW. The efficacy of a behavioral activation intervention among depressed US Latinos with limited English language proficiency: Study protocol for a randomized controlled trial. Trials. 2014; 15:231. [DOI:10.1186/1745-6215-15 231] [PMID] [PMCID]

[8] Kanter JW, Baruch DE, Gaynor ST. Acceptance and commitment therapy and behavioral activation for the treatment of depression: Description and comparison. The Behavior Analyst. 2006; 29(2):161 85. [DOI:10.1007/BF03392129] [PMID] [PMCID]

[9] Samaan Z, Dennis BB, Kalbfleisch L, Bami H, Zielinski L, Bawor M, et al. Behavioral activation group therapy for reducing depressive symptoms and improving quality of life: A feasibility study. Pilot and
Feasibility Studies. 2016; 2:22. [DOI:10.1186/s40814-016-0064-0] [PMID] [PMCID]

[10] McIndoo CC, File AA, Preddy T, Clark CG, Hopko DR. Mindfulnessbased therapy and behavioral activation: $\mathrm{A}$ randomized controlled trial with depressed college students. Behaviour Research and Therapy. 2016; 77:118-28. [DOI:10.1016/j.brat.2015.12.012] [PMID]

[11] Dimidjian S, Hollon SD, Dobson KS, Schmaling KB, Kohlenberg RJ, Addis $\mathrm{ME}$, et al. Randomized trial of behavioral activation, cognitive therapy, and antidepressant medication in the acute treatment of adults with major depression. Journal of Consulting and Clinical Psychology. 2006; 74(4):658-70. [DOI:10.1037/0022-006X.74.4.658] [PMID]

[12] Dobson KS, Hollon SD, Dimidjian S, Schmaling KB, Kohlenberg RJ, Gallop RJ, et al. Randomized trial of behavioral activation, cognitive therapy, and antidepressant medication in the prevention of relapse and recurrence in major depression. Journal of Consulting and Clinical Psychology. 2008; 76(3):468-77. [DOI:10.1037/0022 006X.76.3.468] [PMID] [PMCID]

[13] Pankowski S, Adler M, Andersson G, Lindefors N, Svanborg C. Group Acceptance and Commitment Therapy (ACT) for bipolar disorder and co-existing anxiety: An open pilot study. Cognitive Behaviour Therapy. 2017; 46(2):114-28. [DOI:10.1080.16506073.2016.1231218] [PMID]

[14] Tamannaeifar S, Gharraee B, Birashk B, Habibi M. A comparative effectiveness of Acceptance and Commitment Therapy (ACT) and group cognitive therapy for major depressive disorder. Zahedan Journal of Research in Medical Sciences (ZJRMS). 2014; 16(10):60-63.

[15] Villatte JL, Vilardaga R, Villatte M, Plumb Vilardaga JC, Atkins DC, Hayes SC. Acceptance and Commitment Therapy (ACT) modules: Differential impact on treatment processes and outcomes. Behaviour Research and Therapy. 2015; 77:52-61. [DOI:10.1016/j. brat.2015.12.001] [PMID] [PMCID]

[16] Polk KL, Schoendorff B, Webster M, Olaz FO. The essential guide to the ACT Matrix: A step-by-step approach to using the ACT Matrix model in clinical practice. Oakland, CA: New Harbinger; 2016.

[17] Hayes SC1, Wilson KG, Gifford EV, Follette VM, Strosahl K. Experiential avoidance and behavioral disorders: A functional dimensional approach to diagnosis and treatment. Journal of Consulting and Clinical Psychology. 1996; 64(6):1152-68. [DOI:10.1037/0022 006X.64.6.1152] [PMID]

[18] Peymannia B, hamid N, Mahmudalilu M. The effectiveness of ACT Matrix with compassion on self-injury behaviors and quality of life of Students with symptoms of Borderline Personality Disorders (BPD). Journal of Psychological Achievements. 2018; 25(1):23-44 [DOI:10.22055/psy.2018.23581.1905]

[19] Mirsharifa SM, Mirzaian B, Dousti Y. The efficacy of Acceptance and Commitment Therapy (ACT) Matrix on depression and psychological capital of the patients with irritable bowel syndrome. Open Access Macedonian Journal of Medical Sciences. 2019; 7(3):421-7. [DOI:10.3889/oamjms.2019.076] [PMID] [PMCID]

[20] Lejuez CW, Hopko DR, Acierno R, Daughters SB, Pagoto SL. Ten year revision of the brief behavioral activation treatment for depression: Revised treatment manual. Behavior Modification. 2011; 35(2):111 161. [DOI:10.1177/0145445510390929] [PMID]

[21] Dabson KS, Mohamadkhani P. Psychometric characteristics of Beck Depression Inventory-2 in patients with major depressive disorder. Journal of Rehabilitation. 2007; 8(suppl. 29): 82-88.

[22] Nieto Fernández E, Barraca Mairal J. Behavioral activation versus cognitive restructuring to reduce automatic negative thoughts 
in anxiety generating situations. Psicothema. 2017; 29(2):172-7. [DOI:10.7334/psicothema2016.325] [PMID]

[23] Veale D. Behavioural activation for depression. Adv Psychiatr Treat. 2008;14(1):29-36. [DOI:10.1192/apt.bp.107.004051]

[24] Mirzaee V, Sayyadi B, Hasani Moghaddam V. Comparison of depression patients with irritable bowel syndrom and non-infected patients in referrals to the offices of Rafsanjan specialists in the summer 2010. Journal of Rafsanjan University of Medical Science. 2012; 11(3):259-68.

[25] Kovács Z, Kovács F. Depressive and anxiety symptoms, dysfunctional attitudes and social aspects in irritable bowel syndrome and inflammatory bowel disease. International Journal of Psychiatry in Medicine. 2007; 37(3):245-55. [DOI:10.2190.PM.37.3.a] [PMID]

[26] Forman EM, Herbert JD, Moitra E, Yeomans PD, Geller PA. A randomized controlled effectiveness trial of acceptance and commitment therapy and cognitive therapy for anxiety and depression. Behavior Modification. 2007; 31(6):772-99. [DOI:10.1177/0145445507302202 PMid:17932235] [PMID]

[27] Wu LM, Sheen JM, Shu HL, Chang SC, Hsiao CC. Predictors of anxiety and resilience in adolescents undergoing cancer treatment. Journal of Advanced Nursing. 2013; 69(1):158-66. [DOI:10.1111/ j.1365-2648.2012.06003.x PMid:22489627] [PMID]

[28] Manzano-García G, Ayala JC. Relationship between psychological capital and psychological well-being of direct support staff of specialist autism services: The mediator role of burnout. Frontiers in Psychology. 2017; 8:2277. [DOI:10.3389/fpsyg.2017.02277] [PMID] [PMCID]

[29] 39. Zettle RD, Hayes SC. Dysfunctional control by client verbal behavior: The context of reason-giving. The Analysis of Verbal Behavior. 1986; 4:30-8. [DOI:10.1007/BF03392813] [PMID] [PMCID]

[30] González-Fernández S, Fernández-Rodríguez C, Paz-Caballero MD, Pérez-Álvarez M. Treating anxiety and depression of cancer survivors: Behavioral activation versus acceptance and commitment therapy. Psicothema. 2018; 30(1):14-20. [DOI:10.7334/psicothema2017.396] [PMID]

[31] Baradaran M, Zare H, Alipuor A, Farzad V. [Comparison of effectiveness of acceptance and commitment therapy and motivational interviewing on decreasing anxiety, depression, stress and increasing hope in essential hypertensive patients (Persian)]. Clinical Psychology. 2016; 8(4):95-105.

[32] Hou WK, Ng SM. Emotion-focused positive rumination and relationship satisfaction as the underlying mechanisms between resilience and psychiatric symptoms. Personality and Individual Differences. 2014; 71:159-64. [DOI:10.1016/j.paid.2014.07.032]

[33] Pedersen ER, Paves AP. Comparing perceived public stigma and personal stigma of mental health treatment seeking in a young adult sample. Psychiatry Research. 2014; 219(1):143-50. [DOI:10.1016/j. psychres.2014.05.017] [PMID] [PMCID]

[34] Ohayon MM, Roberts LW. Links between occupational activities and depressive mood in young adult populations. Journal of Psychiatric Research. 2014; 49:10-7. [DOI:10.1016/j.jpsychires.2013.10.002] [PMID]

[35] Miller EJ, Chung H. A literature review of studies of depression and treatment outcomes among U.S. college students since 1990 Psychiatric Services (Washington, D.C.). 2009; 60(9):1257-60. [DOI:10.1176/ps.2009.60.9.1257] [PMID] 